\title{
Occupational exposure to solvents and hairy cell leukaemia
} Jacqueline Clavel, Laurence Mandereau, Françoise Conso, Jean-Claude Limasset,
Isabelle Pourmir, Georges Flandrin, Denis Hémon
Institut National de la Santé et de la Recherche Médicale, INSERM U 170, Villejuif, France J Clavel

L Mandereau

I Pourmir

D Hémon

Service de Pathologie Professionnelle, Hôpital Cochin, Paris, France

F Conso

Institut National de

Recherche et de Sécurité, Nancy, France

J-C Limasset

Laboratoire Central d'Hématologie, Hôpital Necker, Paris, France

G Flandrin

Correspondence to: Dr J Clavel, INSERM U 170, 16 Avenue Paul

Vaillant-Couturier, F-94807

Villejuif Cedex, France

Accepted 10 July 1997

\begin{abstract}
Objectives-The role of occupational exposures in hairy cell leukaemia was investigated through a multicentre, hospital based, case-control study. This paper analyses the role of exposure to solvents other than benzene in hairy cell leukaemia.
\end{abstract}

Methods-The study included 226 male cases and 425 matched controls. exposure to solvents was evaluated by expert case by case review of the detailed data on occupational exposures generated by specific interviews. Also, exposure to solvents was evaluated with an independantly constructed job exposure matrix (JEM).

Results-No association was found between hairy cell leukaemia and previous employment in a job exposed to solvents (odds ratio (OR) $0.9 \quad 95 \%$ confidence interval (95\% CI) 0.6 to 1.3$)$. ORs for the main occupational tasks exposed to solvents were around 1 and did not increase with the frequency or the duration of the tasks. No specific type of paint or glue was found to be significantly associated with hairy cell leukaemia. No association was found with exposure to solvents, taken as a whole, with either expert assessments or the JEM. No association was found with aromatic, chlorinated, or oxygenated subgroups of solvents. The ORs did not increase with the average intensity of exposure assessed by the experts, with the frequency of use, or with the duration of exposure. Finally, no association was found with non-occupational exposure to solvents.

Conclusions-The study did not show any association between exposure to solvents and hairy cell leukaemia.

(Occup Environ Med 1998;55:59-64)

Keywords: case-control; leukaemia; hairy cell; solvents

Hairy cell leukaemia is a particular form of chronic lymphoid leukaemia with an imbalanced male:female sex ratio of about $4: 1$, which suggested the possibility of an occupational risk factor. ${ }^{1}$ Only a few studies have investigated the role of occupational exposures in this rare leukaemia for which large series are difficult to collect. However, the narrow definition of hairy cell leukaemia makes it an interesting model as its aetiology might be less heterogeneous than those of the more common groups of leukaemias. The role of organic solvents in hairy cell leukaemia was suspected in a series report ${ }^{1}$ and in two case-control studies. ${ }^{2}{ }^{3}$ The role of organic solvents has also been suggested in other chronic lymphoid malignancies - that is, in chronic lymphoid leukemia, ${ }^{45}$ nonHodgkin's lymphomas, ${ }^{6-9}$ and myelomas. ${ }^{10}{ }^{11} \mathrm{It}$ has been suggested that solvents could play a part in B cell malignancies through alteration of the immune response. ${ }^{12} 13$

Organic solvents are extensively used in occupational and non-occupational activities. Several types of solvents are often used simultaneously or successively for the same task, making retrospective assessment of the exposure quite complex. The present paper reports the analysis of a large case-control study including 226 male cases of hairy cell leukaemia and 425 matched controls. The study focused on occupational risk factors and was specifically designed for retrospective assessment of solvents and pesticides by experts. Specific analyses on the exposure to benzene and pesticides have been reported elsewhere. ${ }^{1415}$

\section{Subjects and methods}

\section{SELECTION OF CASES AND CONTROLS}

Retrospective recruitment of cases and controls was conducted in 18 hospitals spread through most of France (Angers, Bayonne, Bordeaux, Caen, Chambéry, Lille, Limoges, Lyon, Nancy, Nantes, Nice, Nimes, Paris, Poitiers, Rennes, Rouen, Strasbourg, Toulouse). All the cases, including dead patients, diagnosed from January 1980 to January 1990, were identified and recorded, but data were only obtained from the survivors. All diagnoses were histologically confirmed.

The controls were selected from the admission lists of inpatients for the same 10 year period as for cases. The choice of the source departments for controls was mainly governed by the practical need to target the same age bracket as that of the cases, without preferentially selecting certain diseases (especially those related to occupational exposures, smoking, or alcohol consumption), habits, or socioeconomic status, and by the need to concentrate retrospective sampling on a restricted number of admission records in each city. Thus, controls were mainly recruited in orthopaedic and rheumatological departments. Subjects admitted for malignant disease, disease related to occupation, or work accidents were not eligible as controls. Controls were individually matched with each case on the basis of sex, 
birth date ( \pm 3 years), admission date ( \pm 3 years) and residence (inside or outside the administrative area-département - in which the hospital was located). An attempt was made to match two controls with each case.

The cases and controls were posted a questionnaire designed for self administration. Non-responders were sent the questionnaire up to twice more. If a control had not responded after three requests to do so, he was replaced by another control selected from the list with the same selection criteria.

In all, 378 male cases were identified from the records of 18 haematology departments. From these, 226 living cases $(60 \%)$ were included. Out of the 152 cases excluded, 100 had died (68 before 1984), and 52 did not return the questionnaire. A total of 809 men were eligible as controls and were posted the questionnaire. The completed questionnaire was returned by 465 potential controls ( $57 \%$ ). Forty responders had to be excluded because their individually matched cases were dead or non-responders and because they could not be matched with other cases. A total of 425 male controls was thus finally included.

Finally, $30 \%$ of the cases were matched with a single control, $56 \%$ with two controls, and $14 \%$ with three to five controls.

\section{DATA COLLECTION}

The self administered questionnaires included questions on sociodemographic characteristics, tobacco smoking, lifelong occupations, and leisure activities. Complementary questionnaires were given to subjects when professional exposure to organic solvents was suspected. The interviews were conducted by telephone, by occupational health physicians who had received specialised training.

Specific semistructured questionnaires were designed to allow the experts to conduct case by case reviews to assess exposure to solvents. The questionnaires included both open questions to elicit description of the workplace and closed questions to define the tasks accomplished, products handled, and working conditions. Specialised questionnaires were used for garage workers (mechanical maintenance and bodywork repair tasks), for the exposures of machine tool operators, fitters, and mechanics who degreased metal parts and for all other jobs involving degreasing (glass, textiles, etc), for work involving the use of paints or adhesives, and for printing industry workers. For laboratory and chemical industry workers, the interview simply covered, in detail, a description of the work station, products used, and working conditions, and no specific questionnaire was used.

\section{EXPOSURE DEFINITION}

Jobs were coded with International Labour Organisation (ILO) nomenclature ${ }^{16}$ and industrial sectors with international standard industrial classification (ISIC) nomenclature. ${ }^{17}$ Only jobs lasting at least six months were considered.

Two of us who have extensive experience in industrial health and hygiene (FC and JCL), conducted a case by case assessment of exposure to solvents, blind to case or control status. They reviewed the consistency of the subjects' statements with respect to calendar period, type of industry, job title, and type of exposure. They then assessed the type of solvent used and the probable intensity of the exposure on a scale of low, medium, or high. The intensity of exposure was first assessed for each task described in the specific questionnaire. Then, intensity was determined for a given job as the mean of the intensities of exposures for its constitutive exposing tasks, weighted by the duration of those tasks. Finally, we reviewed our judgments and standardised them across tasks and jobs. ${ }^{18}$ Only exposures encountered for at least one hour a month were considered to focus on more reliable exposures.

Also, an independent assessment of the exposure to solvents was made with the job exposure matrix (JEM) which had been set up for a European study on laryngeal cancer coordinated by the International Agency for Research on Cancer (IARC). ${ }^{19}$ The lines of the JEM were combinations of job titles (ILO codes) and economic activities (ISIC codes). The JEM considered organic solvents as a whole, with no detail on chemical subcategories. The JEM classified the ILO-ISIC combinations into seven categories of exposure, according to the probability and intensity of exposure in a given job. Unexposed jobs were coded 1 and unevaluable or possibly exposed jobs were coded 2 . The certainly exposed categories were coded as follows: category 3 for jobs which may have entailed exposure to levels definitely higher than those for the general population, further divided according to the expected frequency of exposure in the corresponding ILO-ISIC combination (levels 3.1, $3.2,3.3$ for jobs with less than $1 / 3$, between $1 / 3$ and $2 / 3$ and $>2 / 3$ of exposed subjects, respectively), category 4 for jobs certainly exposed, and category 5 for jobs certainly exposed at a particularly high level. The JEM directly covered $74.5 \%$ of the ILO-ISIC combinations encountered in our data. The economic activity for employment in sales or transportation had to be recoded because the original JEM used a modified ISIC code. Most of the missing combinations fitted the matrix by combining the complete ILO code and the two first digits of the ISIC code. The remaining missing combinations were transformed into simplified combinations constituted either by the three digit ILO codes and two digit ISIC codes or by the five digit ILO code alone. The simplified combinations generally corresponded to several lines of the original JEM sometimes with different categories of exposure. Thus, if the competing categories of exposure included at least one category unexposed (1) and one category exposed $(\geqslant 3)$, the category " 3.1 " was chosen, indicating that the job sometimes entailed higher exposure than that for the general population. If all the lines corresponded to exposed categories, the lowest category was chosen. Table 1 shows the percentage of job periods the experts classified as exposed for each JEM category. The two classifications are 
Table 1 Distribution of job periods according to $\mathcal{F E M}$ and percentage of patients classified as exposed by case by case expert assessment

\begin{tabular}{llcc}
\hline fEM & Category of exposure & fob periods $(n)$ & Exposed subjects (\%) \\
\hline 1 & Unexposed & 1958 & 10 \\
2 & Possibly exposed / unevaluable & 121 & 7 \\
3.1 & <1/3 probably exposed & 404 & 23 \\
3.2 & $1 / 3$ to $2 / 3$ probably exposed & 52 & 52 \\
3.3 & $>2 / 3$ probably exposed & 69 & 40 \\
4 & Certainly exposed & 155 & 73 \\
5 & Certainly highly exposed & 51 & 94 \\
\hline
\end{tabular}

Table 2 Sociodemographic characteristics of cases and controls

\begin{tabular}{lcc}
\hline & Cases (226) & Controls (425) \\
\hline Age: & 55.6 & 56.0 \\
Mean & 0.7 & 0.5 \\
SEM & & \\
Socioeconomic status (last job held) (\%): & 29.7 & 27.3 \\
$\quad$ Professional, technical workers, & 24.8 & 26.3 \\
$\quad$ administrators, and managers & 44.7 & 45.9 \\
Clerical, sales, and service workers & 0.4 & 0.0 \\
Production and agricultural workers & 0.4 & 0.5 \\
Never employed & & 18 \\
Unknown & 21 & 33 \\
School level (highest diploma): & 32 & 32 \\
No diploma & 31 & 16 \\
Primary school & 15 & 4.8 \\
Junior school & & 0.1 \\
High school or university graduate & 4.7 & \\
Number of jobs held: & 0.2 & \\
Mean & & \\
SEM & & \\
\hline
\end{tabular}

broadly parallel, except for the categories 3.3 and 4; this departure may, at least in part, be due to the algorithm we used for missing combinations which tends to overestimate the 3.1 category.

Lifelong exposures were used for the analysis. However, two time windows were also considered: one for early exposures - that is, from the beginning of professional life up to 20 years before diagnosis-and one for recent exposures-that is, the last 20 year period before diagnosis.

STATISTICAL ANALYSIS

The odds ratios (ORs) were estimated by conditional logistic regression for matched sets, with a variable number of controls per pair, using SAS procedure PHREG. ${ }^{20}$ The OR estimates are given with their corresponding 95\% confidence intervals (95\% CIs).

CONFOUNDING, EFFECT MODIFICATION, AND BIAS In previous analyses of these data, a clear cut negative association between smoking and hairy cell leukaemia was found with the ORs decreasing with increasing daily cigarette consumption, and lower ORs among current smokers than among former smokers. ${ }^{21}$ The smoking habits of the control group were very similar to those of the general population. This finding was consistent with findings from other case-control studies on hairy cell leukaemia. ${ }^{23}$ Smoking was therefore considered to be a potential confounder or effect modifier in the analysis. A history of farm work was also found to be associated with hairy cell leukaemia in a previous analysis, ${ }^{15}$ and this factor was therefore also taken into account. Finally, a detailed analysis showed no association with benzene exposure, ${ }^{14}$ at the low levels experienced by the study subjects employed during the 1940 s to 1980s in France.

Because of the high proportion of prevalent cases in the study sample, the analysis was also restricted to pairs in which the cases were diagnosed after 1984, when interferon- $\alpha$ became available for therapeutic use and resulted in a threefold reduction in mortality (about $15 \%$ of cases diagnosed after 1984 had died).

\section{Results}

COMPARABILITY OF CASES AND CONTROLS

As table 2 shows, matching resulted in satisfactory case-control comparability for age, socioeconomic status, educational level, and lifelong number of jobs held.

\section{PREVIOUS JOBS EXPOSED TO SOLVENTS}

Of the cases $33 \%$ and of the controls $41 \%$ had been employed for at least six months in a job supposed to involve exposure to solvents (OR 0.9 (95\% CI 0.6 to 1.3$))$. No significant association was found with any of the jobs involving exposure to solvents (table 3). Numbers were small for some jobs such as painters, printers, or dry cleaners. Increased ORs were found for two highly exposed jobs, spray painters and dry cleaners, but they were not significantly different from unity. Similar estimates were obtained for jobs which had lasted at least five years.

OCCUPATIONAL TASKS WITH EXPOSURE TO SOLVENTS

Table 4 shows the ORs for the main tasks exposed to solvents. No association was found.

Table 3 Relation between hairy cell leukaemia and earlier jobs involving exposure to organic solvents

\begin{tabular}{lcccll}
\hline fob titles (ILO codes) & Cases (226) & Controls (425) & OR & (95\% CI) & $p$ Value \\
\hline Painters (8.19.55-8.73.70-9.3) & 6 & 15 & 1.0 & $(0.3$ to 3.0$)$ & NS \\
Spray painters (8.73.70-9.39) & 5 & 7 & 2.0 & $(0.5$ to 8.0$)$ & NS \\
Artists and designers (1.61-1.62) & 1 & 2 & 1.3 & $(0.1$ to 16.7) & NS \\
Printers (9.2) & 3 & 4 & 1.4 & $(0.2$ to 8.5$)$ & NS \\
Cabinet makers, joiners (8.1-9.54) & 12 & 30 & 0.7 & $(0.3$ to 1.6$)$ & NS \\
Shoe and leather goods makers (8.0) & 2 & 6 & 0.9 & $(0.2$ to 5.0) & NS \\
Mechanics (8.43-8.44-8.49) & 18 & 56 & 0.7 & $(0.4$ to 1.2$)$ & NS \\
Electrical fitters (8.5) & 18 & 36 & 1.1 & $(0.5$ to 2.1$)$ & NS \\
Machine tool operators (8.32-8.33-8.34-8.41) & 14 & 45 & 0.7 & $(0.4$ to 1.4$)$ & NS \\
Plumbers (8.71) & 6 & 10 & 1.7 & $(0.6$ to 5.3$)$ & NS \\
Rubber and plastic product makers (9.0) & 3 & 4 & 1.7 & $(0.4$ to 7.8$)$ & NS \\
Chemical industry ${ }^{\star}$ & 7 & 4 & 0.5 & $(0.2$ to 1.4$)$ & NS \\
Housekeepers (5.5) & 1 & 2 & 2.5 & $(0.6$ to 9.8$)$ & NS \\
Launderers and dry cleaners (5.6) & 75 & 176 & 3.0 & $(0.2$ to 49.2$)$ & NS \\
At least one of the previous jobs & & & 0.9 & $(0.6$ to 1.3$)$ & NS \\
\hline
\end{tabular}

$\star$ ISIC code $=351.352 .353$.

$\mathrm{OR}=$ odds ratio estimated with conditional logistic regression, in which the baseline category consists of unexposed workers, adjusted for smoking and farming. 
Table 4 OR associated with main occupational tasks exposed to organic solvents

\begin{tabular}{|c|c|c|c|c|c|c|c|c|c|}
\hline & \multicolumn{3}{|c|}{ Painting } & \multicolumn{3}{|l|}{ Gluing } & \multicolumn{3}{|c|}{ Degreasing } \\
\hline & $\mathrm{ca} / \mathrm{co}$ & $O R$ & $(95 \% C I)$ & $\mathrm{ca} / \mathrm{co}$ & $O R$ & $(95 \% C I)$ & $\mathrm{ca} / \mathrm{co}$ & OR & $(95 \% C I)$ \\
\hline \multicolumn{10}{|c|}{ Possibly exposed self declared tasks: } \\
\hline All & $56 / 93$ & 1.1 & $(0.7$ to 1.6$)$ & $40 / 87$ & 0.9 & $(0.6$ to 1.4$)$ & $51 / 106$ & 0.9 & $(0.6$ to 1.4$)$ \\
\hline Regular^ & $18 / 34$ & 1.2 & (0.6 to 2.2$)$ & $11 / 34$ & 0.6 & $(0.3$ to 1.2$)$ & $26 / 49$ & 1.0 & $(0.6$ to 1.7$)$ \\
\hline \multicolumn{10}{|c|}{ Exposed tasks evaluated by experts (at least $1 \mathrm{~h}$ per month): } \\
\hline All & $24 / 54$ & 0.8 & $(0.5$ to 1.4$)$ & $10 / 21$ & 1.1 & $(0.5$ to 2.8$)$ & $55 / 127$ & 0.9 & $(0.6$ to 1.4$)$ \\
\hline \multicolumn{10}{|c|}{ Average frequency of use: } \\
\hline Low & $7 / 20$ & 0.6 & $(0.2$ to 1.5$)$ & $3 / 12$ & 0.6 & $(0.2$ to 2.3$)$ & $27 / 60$ & 0.9 & (0.5 to 1.6$)$ \\
\hline Medium & $6 / 17$ & 0.7 & $(0.2$ to 1.8$)$ & & & & $13 / 48$ & 0.6 & (0.3 to 1.3$)$ \\
\hline High & $10 / 17$ & 1.0 & $(0.4$ to 2.5$)$ & $7 / 9$ & 2.2 & $(0.7$ to 7.4$)$ & $10 / 14$ & 1.3 & (0.5 to 3.2$)$ \\
\hline \multicolumn{10}{|c|}{ Total duration (y): } \\
\hline$\leqslant 5$ & $6 / 18$ & 0.8 & $(0.3$ to 2.1$)$ & & & & $10 / 31$ & 0.7 & $(0.3$ to 1.7$)$ \\
\hline $6-15$ & $6 / 15$ & 0.6 & $(0.2$ to 1.8$)$ & $5 / 10$ & 1.3 & (0.4 to 4.4$)$ & $17 / 30$ & 1.5 & (0.7 to 2.9$)$ \\
\hline$>15$ & $12 / 20$ & 1.0 & $(0.4$ to 2.1$)$ & $5 / 11$ & 1.1 & $(0.3$ to 3.4$)$ & $24 / 61$ & 0.7 & (0.4 to 1.3 ) \\
\hline
\end{tabular}

*At least once a week.

$\mathrm{OR}=$ odds ratio estimated with conditional logistic regression, in which the baseline category consists of unexposed workers, adjusted for smoking and farming. $\mathrm{ca} / \mathrm{co}=$ Cases/controls.

Odds ratios did not increase with either the frequency or the duration of the tasks evaluated by the experts.

OCCUPATIONAL EXPOSURE TO SOLVENTS No association was found with exposure to solvents, taken as a whole, by either our expert judgement or the JEM (table 5).

The OR was also close to unity for subjects classified as exposed to organic solvents by both the experts and the JEM, even at a high level.

Most of the chlorinated exposure to solvents were to trichloroethylene. No case, but eight controls were exposed to methylene chloride. No association was found with any of the other subgroups of solvents.

Table 5 OR associated with solvent exposure as assessed by expert or $\mathcal{F E M}$

\begin{tabular}{lrrll}
\hline & Cases & Controls & OR & (95\% CI) \\
\hline Expert: & & & & \\
$\quad$ Unexposed & 145 & 255 & 1.0 & - \\
$\quad$ Exposed (at least 1h per month) & 71 & 154 & 0.9 & (0.6 to 1.3) \\
JEM: & 112 & 183 & 1.0 & - \\
$\quad$ 1 & 99 & 222 & 0.9 & $(0.6$ to 1.4$)$ \\
$3.1-5$ & 59 & 108 & 1.1 & $(0.7$ to 1.7$)$ \\
$3.1,3.2$ & 32 & 97 & 0.7 & $(0.4$ to 1.2$)$ \\
3.3, 4,5 & 92 & 150 & 1.0 & - \\
Both: & 44 & 88 & 1.1 & $(0.7$ to 1.9$)$ \\
$\quad$ Unexposed and 1 & 18 & 28 & 1.2 & $(0.6$ to 2.7$)$ \\
$\quad$ Unexposed and 3.1-5 & 47 & 123 & 0.8 & $(0.5$ to 1.7$)$ \\
$\quad$ Exposed and 1 & & & \\
$\quad$ Exposed and 3.1-5 & &
\end{tabular}

$\mathrm{OR}=$ odds ratio estimated with conditional logistic regression, in which the baseline category consists of unexposed workers, adjusted for smoking and farming.
The ORs for exposure to solvents did not increase with the average intensity of exposure, with the frequency of use, or with the duration of use (table 6).

The results for occupational exposures were unchanged when the definition of exposure was modified either by restricting the exposure to medium or high intensity, or frequency of exposure, or by extending the exposed category to subjects exposed for less than one hour per month. There was no increase in risk for any solvent when the exposure was restricted to either the recent (20 years preceding diagnosis) or early time windows (at least 20 years before diagnosis).

Finally, the results were not affected when the analysis was restricted to pairs in which cases were diagnosed after 1984 .

NON-OCCUPATIONAL EXPOSURE TO SOLVENT

Non-occupational activities were obtained from the self administered questionnaire. Data were missing in $18 \%$ of the cases and $23 \%$ of the controls. Non-occupational tasks involving paints, adhesives, degreasers, paint removers, or wood preservatives were declared by $48 \%$ of the cases and $53 \%$ of the controls and yielded ORs ranging from 0.7 to 0.9 , with $95 \%$ CIs clearly including 1.0 .

\section{Discussion}

The association between exposure to solvents and hairy cell leukaemia was examined in a case-control study of 226 male cases and 425

Table 6 OR associated with intensity, frequency, and duration of use of main chemical families of organic solvents

\begin{tabular}{|c|c|c|c|c|c|c|c|c|}
\hline & \multicolumn{2}{|c|}{ All organic solvents } & \multicolumn{2}{|c|}{ Chlorinated } & \multicolumn{2}{|c|}{ Aromatic } & \multicolumn{2}{|c|}{ Oxygenated } \\
\hline & $\mathrm{ca} / \mathrm{co}$ & OR $(95 \% C I)$ & $\mathrm{ca} / \mathrm{co}$ & OR $(95 \% C I)$ & $\mathrm{ca} / \mathrm{co}$ & $O R(95 \% C I)$ & $\mathrm{ca} / \mathrm{co}$ & OR $(95 \% C I)$ \\
\hline \multicolumn{9}{|c|}{ Average intensity: } \\
\hline Low & $6 / 9$ & $1.3(0.4$ to 4.1$)$ & $3 / 3$ & $1.5(0.3$ to 8.1$)$ & $5 / 13$ & $0.9(0.3$ to 3.3$)$ & $5 / 5$ & $1.8(0.5$ to 7.3$)$ \\
\hline Medium & $28 / 73$ & $0.9(0.5$ to 1.5$)$ & $26 / 68$ & $0.8(0.5$ to 1.3$)$ & $22 / 56$ & $0.9(0.5$ to 1.6$)$ & $10 / 27$ & $1.0(0.4$ to 2.2$)$ \\
\hline High & $27 / 57$ & $1.0(0.6$ to 1.8$)$ & $8 / 17$ & $0.7(0.3$ to 1.8$)$ & $19 / 48$ & $0.7(0.4$ to 1.4$)$ & $13 / 21$ & $1.4(0.6$ to 3.1$)$ \\
\hline \multicolumn{9}{|c|}{ Average frequency of use: } \\
\hline Low & $24 / 62$ & $0.8(0.5$ to 1.5$)$ & $23 / 58$ & $0.7(0.4$ to 1.3$)$ & $20 / 49$ & $0.8(0.4$ to 1.5$)$ & $9 / 26$ & $0.8(0.3$ to 2.0$)$ \\
\hline Medium & $12 / 16$ & $2.4(0.9$ to 6.2$)$ & $4 / 11$ & $0.7(0.2$ to 2.8$)$ & $7 / 17$ & $1.1(0.4$ to 3.2$)$ & $7 / 5$ & $3.3(0.9$ to 12.1$)$ \\
\hline High & $25 / 61$ & $0.8(0.5$ to 1.5$)$ & $10 / 19$ & $1.1(0.5$ to 2.6$)$ & $19 / 51$ & $0.8(0.4$ to 1.5$)$ & $12 / 22$ & $1.3(0.6$ to 2.8$)$ \\
\hline \multicolumn{9}{|c|}{ Total duration $(y)$ : } \\
\hline$\leqslant 5$ & $12 / 37$ & $0.8(0.4$ to 1.6$)$ & $8 / 22$ & $0.6(0.3$ to 1.5$)$ & $7 / 37$ & $0.5(0.2$ to 1.2$)$ & $9 / 12$ & $1.9(0.7$ to 4.9$)$ \\
\hline 6 to 15 & $20 / 37$ & $1.3(0.7$ to 2.5$)$ & $13 / 26$ & $1.0(0.5$ to 2.1$)$ & $17 / 33$ & $1.1(0.5$ to 2.3$)$ & $8 / 18$ & $0.9(0.3$ to 2.5$)$ \\
\hline$>15$ & $29 / 65$ & $0.9(0.5$ to 1.6$)$ & $16 / 40$ & $0.8(0.4$ to 1.5$)$ & $22 / 47$ & $0.8(0.5$ to 1.6$)$ & $11 / 23$ & $1.2(0.5$ to 2.7$)$ \\
\hline
\end{tabular}

$\mathrm{OR}=$ odds ratio estimated with conditional logistic regression, in which the baseline category consists of unexposed workers, adjusted for smoking and farming. $\mathrm{ca} / \mathrm{co}=$ Cases/controls. 
matched controls. No association was found with jobs and tasks involving exposure to solvents, or with exposures individually assessed by experts from specific questionnaires. No association was found for chlorinated, aromatic, or oxygenated solvents. In those solvent subgroups, ORs did not increase with intensity, frequency of use, or duration of exposure to solvents. No association was found when exposure to solvents was assessed with a job exposure matrix.

Due to the rarity of the disease, retrospective recruitment was conducted and could have induced some biases. The response rate to the self administered questionnaire was low, but it was similar for cases (60\%) and controls $(57 \%)$. This similarity was not influenced by age or year of admission to hospital. The follow up of cases in their hospital departments allowed us to identify those who had died but this was impossible for controls. However, the comparability of cases and controls in terms of socioeconomic status, educational level, and number of jobs was good. In the present study, as shown in a previous paper, ${ }^{21}$ the smoking habits and socioeconomic status of the control group were very similar to those of the general population in the same age groups. A selection bias is therefore unlikely to mask an association. For practical reasons, the study only examined living cases. If exposure to solvents was related to duration of survival, the design could miss an effect. However, the estimates were very similar when the analysis was restricted to pairs in which the cases were diagnosed after 1984, when survival was threefold higher, because interferon- $\alpha$ became available for therapeutic use. Replacement of nonresponding controls by other eligible controls did not seem to induce a bias as estimates were very similar when analysis was restricted to pairs in which the controls were unreplaced.

The size of the study allowed a power $>80 \%$ for an OR of 2.0, even for high exposures alone. However, the study lacks power for exposures to chemical subtypes of solvents or for employment in some jobs. For instance, an OR of 2.0 was found for spray painters. This job involves high exposure to specific paints, but the study was not powerful enough to investigate this exposure further. Similarly, the role of carbon tetrachloride could not be investigated in our study.

Occupational exposure to solvents is common but heterogeneous. Non-differential misclassifications are probably important in the retrospective process of exposure assessment, even carefully conducted. They could be sufficient to mask an association. However, in the present study, concordant conclusions were drawn with job titles as a surrogate, with a case by case assessment of exposure by experts or with an independently designed JEM for assessment of exposure. The expert assessment took into account more individual information and aimed to provide more precise evaluation of the nature of solvents involved than the other methods. However, it is a more subjective method and a special effort was made to standardise the expert process.
Exposures to paint, glues, degreasers, or wood preservatives during leisure activities were not related to hairy cell leukaemia. These exposure are thus unlikely to be negative confounders for the study of occupational exposure to solvents.

Previous studies on hairy cell leukaemia have suggested, to a limited extent, an association with organic solvents. In the study by Oleske et $a l^{2}$ the exposure of interest was not exactly exposure to solvents but exposure to organic chemicals, with an OR (95\% CI) of 2.5 (1.1 to 5.7). In the study by Bernstein et al $l^{2}$ ORs of 2.0 (1.0 to 4.0 ) and 3.3 (2.1 to 5.6) were associated with last jobs before diagnosis of mechanic and engineer, respectively. The exposure to solvents was investigated by Staines and Cartwright, ${ }^{3}$ who found an OR of 1.5 (0.6 to 3.7) for all exposure to solvents. A small study by McKinney et $a l,{ }^{23}$ did not find any association with solvents.

The role of exposure to solvents has also been suggested in other chronic lymphoid malignancies. For chronic lymphoid leukaemia, an OR of 2 was found by Flodin et $a l,{ }^{4}$ for high exposure to solvents, and Malone et al, ${ }^{5}$ found a slight association with exposure to chlorinated solvents but not with other solvents. However, the Yorkshire study did not show any association with employment as a painter, printer, or worker in the chemical industry $^{24}$ or with exposure to organic solvents. ${ }^{25}$ In the Swedish registry, a slight excess of risk was found for printers and shoe makers but not for painters. ${ }^{26}$ For nonHodgkin's lymphoma, associations have been described with jobs exposed to solvents such as employment in shoe making or shoe repair, ${ }^{27}$ painters, carpenters, and plumbers. ${ }^{28}$ An association with the use of glues was found in the Yorkshire study ${ }^{29}$ but not with solvents. ${ }^{30}$ Associations with occupational exposure to solvents have been found in Sweden, ${ }^{6-9}$ whereas a slight association was limited to diffuse type nonHodgkin's lymphoma in a study in the United States. ${ }^{30}$ For myeloma, an association with employment as a painter has been found in several studies. ${ }^{31}$ In the study by Demers et al, ${ }^{11}$ the association was stronger for the painters who had high exposure to solvents. Morris et $a l^{10}$ found a positive association with exposure to solvents, but a negative association was found by Eriksson and Karlsson. ${ }^{32}$ No association was found between exposure to solvents and lymphopoietic malignancies in the Montreal study. ${ }^{33}$ Cohort studies exposed to trichloroethylene and perchloroethylene showed an increase in the risk of non-Hodgkin's lymphoma, ${ }^{34}$ but no excess of leukaemias. Interestingly, the long term follow up of Swedish subjects who had a disorder related to solvents showed an increase in the risk of haematological malignancies, with a non- significantly increased standardised incidence ratio for leukaemias, lymphomas, and myelomas. ${ }^{35}$

In conclusion, the scientific literature tends to suggest an association between occupationnal exposure to organic solvents and B cell lymphoid malignancies, but studies have not yet provided conclusive evidence. There is still 
a need for studies in various populations. In the case of hairy cell leukaemia, data are sparse and the present study is the first large case-control study with a careful expert assessment of occupational exposure to solvents. Its findings do not support the hypothesis of an association between exposure to solvents and hairy cell leukaemia, but could not rule out an association with subtypes of solvents not evaluated by the experts.

This study was supported by the French Ministère de la Recherche et de la Technologie, the Caisse Régionale d'Assurance Maladie de l'Ile de France, and the Ministère chargé de l'Enseignement Supérieur. We thank Drs Berrino, Boffetta, and Pisani who gave us the opportunity to use the job exposure matrix developed at the Epidemiology Division of the Istituto Nazionale Tumori, Milan under contract CNR No 8800524.44 . We thank Drs Bauters, Bayle, Blanc, Boasson, 8800524.44 . We thank Drs Bauters, Bayle, Blanc, Boasson,
Broustet, Coiffier, Gardais, Gardembas, Fiere, Foussard, Broustet, Coiffier, Gardais, Gardembas, Fiere, Foussard, Guerci, Guilhot, Harousseau, Leporrier, Le Prisé, Malinvaud, Oberling, Pris, Renoux, Troussard, Schved, Streiff, Thyss, Tilly, and Walter, haematologists, for their help in the identification and recruitment of cases. We also thank the heads of the departBallanger, Bazin, Besse, Brissot, Clarac, Devulder, Dubernard, Duquennoy, Durandeau, Ferrand, Gaucher, Jeannaret, Kempf, Lerat, Letenneur, Mansat, Pecout, Thomine, Toubol, Vignon, Ziegler. We are also indebted to Dr Mora, occupational health physician, who conducted most of the specific interviews. We are grateful to $\mathrm{Mr}$ Mullarky for his skilful translation of the manuscript.

1 Flandrin G, Collado S. Is male predominance in hairy cell eukaemia related to occupational exposure to ionizing radiation, benzene and other solvents? $\mathrm{Br} \neq \mathrm{f}$ Haematol 1987;67:119-20.

2 Oleske D, Golomb HM, Farber MD, Levy PS. A case-control inquiry into the etiology of hairy cell leukemia. Am 7 Epidemiol 1985;121:675-83.

3 Staines A, Cartwright RA. Hairy cell leukaemia: descriptive epidemiology and a case-control study. $\mathrm{Br} \mathcal{F}$ Haematol 1993;85:714-7.

4 Flodin U, Fredriksson M, Persson B, Axelson O. Chronic lymphatic leukaemia and engine exhausts, fresh wood and lymphatic leukaemia and engine exhausts, fresh wood and

5 Malone KE, Koepsell TD, Daling JR, et al. Chronic lymphocytic leukemia in relation to chemical exposures. Am f Epidemiol 1989:130:1152-8.

6 Hardell L, Eriksson M, Lenner P, Lundgren E. Malignant lymphoma and exposure to chemicals, especially organic solvents, chlorophenols and phenoxy acids: a case-control study. Br $\mathcal{F}$ Cancer 1981;43:169-76

7 Hardell L, Eriksson M, Degerman A. Exposure to phenoxy acids, chlorophenols, or organic solvents in relation to histopathology, stage, and anatomical localization of nonHodgkin's lymphoma. Cancer Res 1994;54:2386-9.

8 Olsson H, Brandt L. Risk of non-Hodgkin's lymphoma among men occupationally exposed to organic solvents. Scand f Work Environ Health 1988;14:246-51.

9 Persson B, Dahlander AM, Fredriksson M, et al. Malignant lymphomas and occupational exposures. Br f Ind Med 1989;46:516-20.

10 Morris PD, Koepsell TD, Daling JR, et al. Toxic substance exposure and multiple myeloma: a case-control study. $\mathscr{F}$

11 Demers PA, Vaughan TL, Koepsell TD, et al. A case-control study of multiple myeloma and occupation. Am F Ind Med 1993;23:629-39.

12 Brandt L. Leukaemia and lymphoma risks derived from solvents. Medical Oncology and Tumor Pharmacotherapy 1987; 4:199-205
13 Vineis P, D'Amore F, Working group on the epidemiology of hematolymphopoietic malignancies in Italy. The role of ccupational exposure and immunodeficiency in B-cell malignancies. Epidemiology 1992;3:266-70.

14 Clavel J, Conso F, Limasset JC, et al. Hairy cell leukaemia and occupational exposure to benzene. Occup Environ Med 1996;53:533-9.

15 Clavel J, Hémon D, Mandereau L, et al. Farming, pesticide use and hairy cell leukaemia. Scand $\mathcal{F}$ Work Environ Health 1996;22:285-93.

16 International Labour Office. International standard classification of occupations. Revised ed. Geneva: ILO, 1968.

17 United Nations. International standard industrial classification of all economic activities. New York: United Nations, 1975.

18 Clavel J, Glass DC, Cordier S, Hémon D. Standardization in the retrospective evaluation by experts of occupational exposure to organic solvents in a population-based case-control study. Int $\mathcal{f}$ Epidemiol 1993;22(suppl 2): s121-6.

19 Ferrario F, Continenza D, Pisani P, Magnani C, Merletti F, Berrino F. Description of a job-exposure matrix for sixteen agents which are or may be related to respiratory cancer. In: Hogstedt C, Reuterwall C, eds. Progress in occupational epidemiology. Amsterdam: Elsevier, 1988.

20 Ying SO. PROC PHREG: a procedure for Cox's proportional hazards regression analysis. Cary, NC, USA: SAS, 1991.

21 Clavel J, Mandereau L, Cordier S, et al. Hairy cell leukaemia, occupation and smoking. Br f Haematol, 1995; 91:154-61.

22 Bernstein L, Newton P, Ross RK. Epidemiology of hairy cell leukemia in Los Angeles county. Cancer Res 1990;50:36059.

23 McKinney PA, Cartwright RA, Pearlman B. Hairy cell leukaemia and occupational exposures. $\mathrm{Br}$ f Haematol $1984 ; 68: 142-3$.

24 Cartwright RA, Bernard SM, Bird CC, et al. Chronic lymphocytic leukaemia: case-control epidemiological study in Yorkshire. Br 7 Cancer 1987;56:79-82.

25 McKinney PA, Alexander FE, Roberts BE, O'Brien C, Bird CC, Cartwright RA. Yorkshire case control study of leukaemias and lymphomas: parallel multivariate analyses of seven disease categories. Leuk Lymphoma 1990;2:67-80.

26 Linet MS, Malker HSR, McLaughlin JK, et al. Leukemias and occupation in Sweden: a registry-based analysis. Am $\mathcal{F}$ Ind Med 1988;14:319-30.

27 Linet MS, Malker HSR, McLaughlin JK, et al. NonHodgkin's lymphoma and occupation in Sweden: a registry-based analysis. Br f Ind Med 1993;50:79-84

28 Sherr PA, Hutchison GB, Neiman RS. Non-Hodgkin's lymphoma and occupational exposure. Cancer Res 1992;52. 5503 s-9s.

29 Cartwright RA, McKinney PA, O'Brien C, et al. NonHodgkin lymphoma: case-control epidemiological study in Yorkshire. Leukaemia Res 1988;12:81-8.

30 Blair A, Linos A, Stewart PA, et al. Evaluation of risks for non-Hodgkin's lymphoma by occupation and industry exposures from a case-control study. Am f Ind $M e d$ 1993;23:301-12.

31 International Agency for Research on Cancer. IARC monographs on the evaluation of the carcinogenic risk of chemicals to humans. Some organic solvents, resin monomers, pigments and occupational exposures in paint manufacture and painting. Vol 47. Lyon, France: IARC, 1989

32 Eriksson M, Karlsson M. Occupational and other environmental factors and multiple myeloma. Br f Ind Med 1992; 49:95-103.

33 Siemiatycki J, Gerin M, Dewar R, et al. Associations between occupational circumstances and cancer. In: Siemiatycki, ed. Risks factors for cancer in the workplace. Boca Raton: CRC Press, 1991.

34 International Agency for Research on Cancer. IARC monographs on the evaluation of the carcinogenic risk of chemicals to umans. Dry cleaning, some chlorinated and of hemicals. Vol 63. Lyon, France: IARC 1995.

35 Berlin K, Edling C, Persson B, et al. Cancer incidence and mortality of patients with suspected solvent-related disorders. Scand f Work Environ Health 1995;21:362-67. 